Creeth, J. M., KeKWick, R. A., Flynn, F. V., HARRIS, H., and RoBSON, E. B. (1963): An Ultracentrifuge Study of Urine Proteins with Particular Reference to the Proteinuria of Renal Tubular Disorders, Clin. Chim. Acta, 8, 406.

DENT, C. E., and HaRris, H. (1951): The Genetics of Cystinuria, Ann. Eugen. (Lond.), 16, 60.

ENGLE, R. L. Jr., and Wallis, L. A. (1956): Multiple Myeloma and the Adult Fanconi Syndrome; Report of a Case with Crystal-like Deposits in the Tumour Cells and in the Epithelial Cells of the Kidney, Amer. J. med., 21, 5.

Gross, J. M., (1963): Fanconi Syndrome (Adult type) Developing Secondary to Ingestion of Outdated Tetracycline, Ann. intern. med., 58, 523.

Kazantzis, G., FlynN, F. V., Spowage, J. S., and TrotT, D. G. (1963): Renal Tubular Malfunction and Pulmonary Emphysema in Cadmium Workers, Quart. J. med., 32, 165.
Linder, G. C., Bull, G. M., and Grayce, I. (1949): Hypophosphatemic Glycosuric Rickets (Fanconi Syndrome) - Report of a Case with Retinitis Pigmentosa, Clin. Proc., 8, 1.

Morgan, H. G., Stewart, W. K., Lowe, K. G., STOWERS, J. M., and JOHNSTONE, J. H. (1962): Wilson's Disease and the Fanconi Syndrome, Quart. J. med., 31, 361 .

Stanbury, S. W., and Lumb, G. A. (1962): Metabolic Aspects of Renal Osteodystrophy, I. Medicine (Baltimore), 41, 1.

Wallis, L. A., and Engle, R. L. (1957): Adult Fanconi Syndrome. Review of Eighteen Cases, Amer. J. Med., 22, 13

Wilson, D. R., and YendT, E. R. (1963): Treatment of the Adult Fanconi Syndrome with Oral Phosphate Supplements and Alkali, Amer. J. Med., 35, 487.

\title{
A SOLITARY SECONDARY DEPOSIT IN THE PANCREAS FROM A CARCINOMA OF THE CERVIX
}

\author{
C. WASTEll, F.R.C.S. \\ Westminster Hospital, London, S.W.I
}

SECONDARY deposits in the pancreas from carcinomas elsewhere are quite commonly found but solitary secondary deposits are rare.

The following case is sufficiently unusual to warrant a brief report.

\section{Case Report}

A lady aged 66 was admitted to Westminster Hospital in August 1959 with a stage II carcinoma of the cervix. Biopsy revealed a moderately well differentiated carcinoma (Fig. 1) which was treated with two insertions of radium by the Stockholm technique and a course of external beam radiotherapy with the Theratron unit. A good recovery was made apart from persistent painful micturition, which was worse at night. One year later, at cystoscopy no evidence of recurrent growth was seen, there being some basal trigonitis only.

She remained well until July 1964, some five years after the cervical lesion was first treated, when she presented with a nine week history of jaundice. This was associated with back pain, weight loss, anorexia, dark urine and pale stools.

On Examination. The patient was deeply jaundiced and had obviously lost weight. The abdomen was slightly distended and the smooth, tender liver edge was palpable $8 \mathrm{~cm}$. below the costal margin. Beneath the liver the distended gall bladder could be felt. On pelvic examination the vault of the vagina was found to be obliterated by post-irradiation scarring but there was no evidence of recurrence of tumour.

Investigations: Total serum bilirubin $13.5 \mathrm{mg} . / 100$ $\mathrm{ml}$., Conjugated $9.3 \mathrm{mg}$., free $3.2 / \mathrm{mg}$. $/ 100 \mathrm{ml}$., Serum alkaline phosphatase 31 K.A. units, Prothrombin time: normal. SGOT 34 I.U., S.G.P.T. 19 I.U., Hb. 12.4 g./100 ml., Serum albumin 2.1 g. globulin

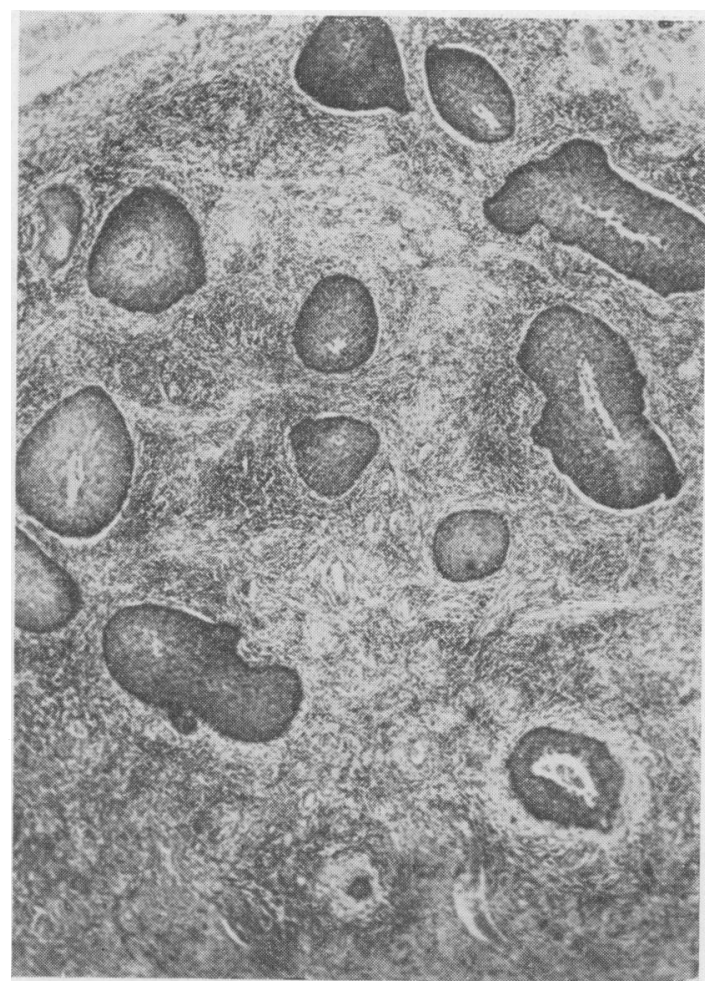

FIG. 1.-Section from biopsy of cervix taken in 1959 showing moderately well differentiated squamous carcinoma. (H. \& E. x 65). 


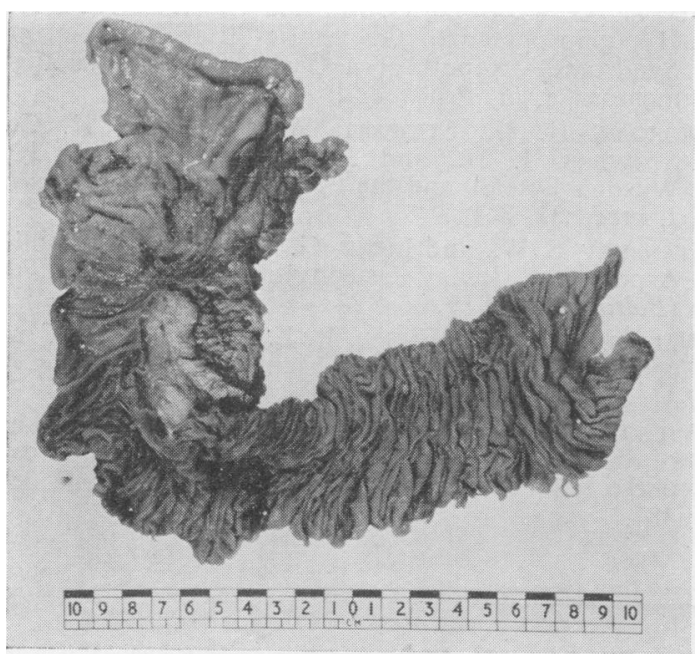

Fig. 2.-Specimen removed at pancreatico-duodenectomy cut open to show tumour infiltrating the medial wall of the duodenum.

$0.7 \mathrm{~g} . / 100 \mathrm{ml}$. X-rays of the abdomen, chest, lumbar spine and sacrum failed to show evidence of gall stones or of secondary deposits.

The most likely diagnosis was thought to be carcinomatosis with hepatic deposits but in a view of the biochemical data which suggested obstructive jaundice and the distended gall bladder it was felt that laparotomy was justified. This was then performed after a preliminary course of intramuscular vitamin $\mathrm{K}$.

Operation. A right upper paramedian incision was made and a hard tumour $2.5 \mathrm{~cm}$. in diameter in the head of the pancreas was found. The gall bladder was distended and the common bile duct dilated. General laparotomy showed the pelvic organs to be atrophic but free from growth and there was no evidence of distant spread elsewhere within the peritoneal cavity.

After preliminary dissection of the head of the pancreas, during which it was found that although it was adherent to the retroperitoneal tissues over the aorta a satisfactory plane could be established, a pancreatico-duodenectomy was performed.

Unfortunately almost immediately on return to the ward the patient inhaled a small quantity of vomit, and required bronchoscopy. On the fourth postoperative day she had a melaena and was given four pints of blood. By the tenth day the total bilirubin had fallen to $6.4 \mathrm{mg} . / 100 \mathrm{ml}$. but the general condition was poor, due principally to persistent chest infection. In spite of antibiotics and intensive physiotherapy the patient went downhill and died on the 16th day.

Pathology examination of the resected duodenum and pancreas (Fig. 2) showed the tumour to be infiltrating the muscle and submucosa of the duodenum. Histological examination (Fig. 3) showed the tumour to be a moderately well differentiated squamous celled carcinoma with appearances exactly similar to those of the biopsy of the carcinoma of cervix obtained in 1959. It was concluded, therefore, that the lesion of the head of the pancreas was a secondary deposit from the carcinoma of the

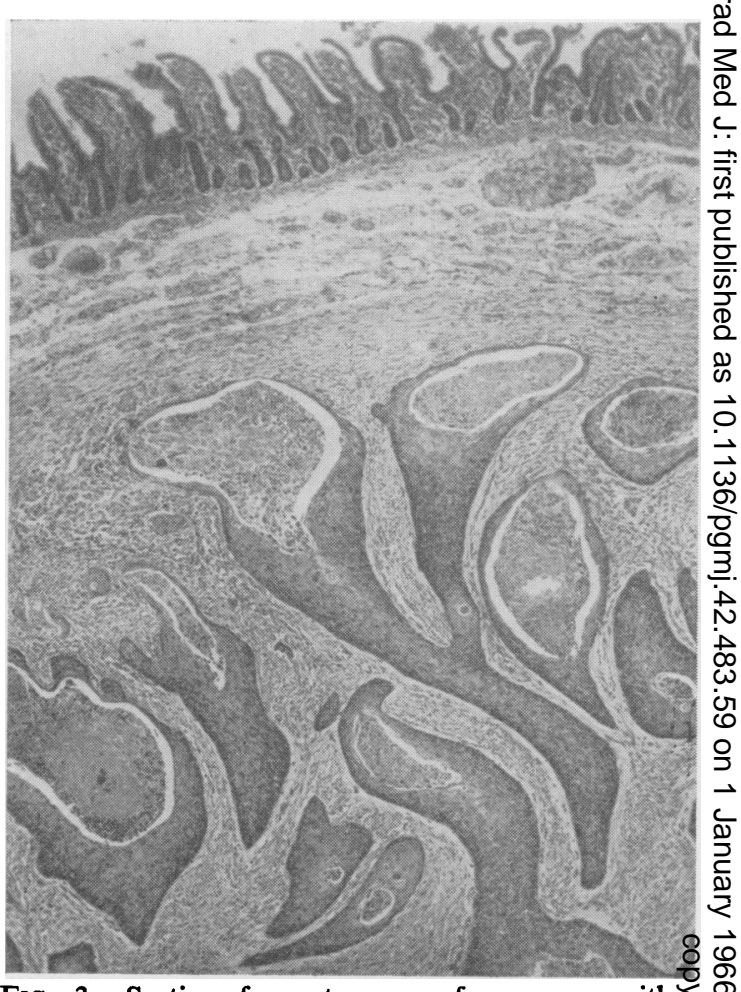

FIG. 3.- Section from tumour of pancreas with similar histological picture to that of Fig. $\bar{\Phi}$. The tumour is infiltrating the muscle wall of the duodenum, the mucosa of which can be seen. (H. \& E. x 65).

cervix which had been treated five years previously. $\frac{\circ}{\Phi}$

Necropsy. The cause of death was found to be $\varrho$ suppurative bronchopneumonia. The anastomoses $\overrightarrow{\overrightarrow{0}}$ were intact but the choledocho-duodenostomy was not 3 patent. There was an abscess containing $40 \mathrm{ml}$. of $\bar{T}$ creamy pus in the region of the cut surface of the pancreas. Dense fibrosis had obliterated the upper vagina and cervical canal, the rest of the pelvic 0 organs were small and atrophic and otherwise normal. There was no macroscopic or microscopic evidence $\bar{\sigma}$ of residual tumour in the pelvis, para-aortic lymph 3 . nodes, or elsewhere.

\section{Discussion}

Solitary secondary deposits from any carcinoma $\stackrel{\circ}{\supset}$ are of considerable surgical importance because $\rightarrow$ they represent the only type of distant malignant dissemination which is amenable to surgical cure. N In addition this patient is particularly interesting in that as far as can be ascertained no other $N$ case of a solitary secondary deposit in the pancreas ${ }_{\mathrm{W}}$ causing obstructive jaundice from a carcinoma of the cervix could be found in previous reports.

The most common mode of spread from $a \stackrel{0}{0}$ carcinoma of the cervix is by direct extension (Willis, 1960), thereafter by invasion of the lym- phatics in a fairly regular pattern (Henrikesen, $\frac{T}{0}$ 1944). Blood-borne metastases may disseminate $\frac{\vec{\Phi}}{\mathbb{O}}$ to almost any tissue of the body but when they? 
do so they are often a late manifestation of the disease and the organs most commonly involved are the liver, lungs, bones and bowel (Arneson and Williams, 1960, Herbut, 1953). The most common histological type is the squamous celled tumour which occurred in nearly $80 \%$ of the series of cases reviewed by Blaikley, Lederman and O' Connor (1962).

In reviewing post-mortem findings in 108 autopsies on patients who had had carcinoma of the cervix, Sotto, Graham, and Pickren (1960) found that, of those in which the pelvis was clear, only $9 \%$ had extrapelvic metastases. In 3\% of this series deposits occurred in the pancreas but it is not stated whether these occurred with or without deposits elsewhere or whether residual growth was present in the pelvis. It was also noted that of 100 patients dying of the treatment or complications of the disease only $8 \%$ did so in the 5 th to 10th post treatment year.

The incidence of both pancreatic deposits and extra-pelvic deposits with a clear pelvis was slightly higher in a series of autopsies performed on patients who underwent radical surgery for cancer of the cervix reviewed by Kelly, Parson, Friedell and Summers, (1960). 16\% had deposits elsewhere but not in the pelvis, and $9 \%$ of all the patients in the series had deposits in the pancreas.

Late recurrence of this cancer has been reported in a number of sites; thus Hawkins and Andres (1935) described a patient who developed a recurrence on the cervix itself which occurred 30 years after treatment with radium. Von Capellar and Cummings (1957) reported a patient who had a solitary duodenal metastasis occurring eight years after treatment of a Stage I carcinoma. They point out, however, that in their patient the deposit may have arisen in the para-aortic lymph nodes and secondarily invaded the duodenum.

The patient reported presents, therefore, a combination of unusual features and the pathology appears to be unique.

\section{Summary}

A patient is described who had a solitary secondary deposit from a neoplasm of the cervix treated by irradiation five years previously, in the head of the pancreas producing obstructive jaundice. In the discussion the exceptional rarity of this case is pointed out.

I would like to thank Professor Harold Ellis and Sir Arthur Bell for allowing me to publish this case, Professor A. Morgan for the report on the histology, and the Westminster photographic department for the photographs.

\section{REFERENCES}

Arneson, A. N., and Williams, C. F. (1960): Long Term Follow Up Observations in Cervical Cancer, Amer. J. Obstet. Gynec., 80, 75.

Blaikley, J. B., Lederman, M., and O'ConNor, K. J. (1962): Carcinoma of Cervix at Chelsea Hospital for Women 1933-60, Lancet ii, 978.

CAPEllar, VoN D., and CUMMINGS, A. S. (1957): Solitary Duodenal Metastasis 8 years after Radiation of Carcinoma of Cervix, Gastroenterology, 33, 655.

HAWkins, J., and ANDREW, J. D. (1935): Reappearance of a Cervical Carcinoma after Treatment with Radium, J. Obstet. Gynaec. Brit. Emp., 62, 870.

HeRBUT, P. A. (1953): Gynaecological and Obstetrical Pathology. London: Henry Kimpton.

HENRIKSEN, E. (1944): The Lymphatic Spread of Carcinoma of the Cervix and of the Body of the Uterus. A Study of 420 Necropsies, Amer. J. Obstet. Gynec., 58, 924.

Kelly, J. W. M., Parson, L., Friedell, G. H., and Summers, S. C. (1960): A Pathologic Study in 55 Autopsies after Radical Surgery for Carcinoma of Cervix, Surg. Gynec. Ostet., 110, 423.

PARENTE, J. T. (1960): Metastases in Cancer of Cervix, Amer. J. Surg., 99, 343.

SoTTO, L. S. J., GRAHAM, J. B., and PICKREN, J. W. (1960): Post Mortem Findings in Cancer of the Cervix. An Analysis of 108 Autopsies in the past 5 years, Amer. J. Obstet. Gynec., 80, 791.

Willis, R. A. (1960): Pathology of Tumours. p. 534. London: Butterworths.

\title{
CHRONIC TOXOPLASMOSIS WITH NEGATIVE DYE TEST?
}

\author{
J. S. RoberTSON, M. B., M.R.C.S., D.P.H., D.I.H. \\ Toxoplasmosis Research Unit, 50 Holydyke, Barton-on-Humber.
}

Although high or rising antibody titres are needed to support a clinical diagnosis of acute toxoplasmosis, low titres to the dye test are believed to indicate past infection. Since the ocular manifestations of toxoplasmosis usually result from long standing chronic infections it is of importance in opthalmic practice to determine whether or not a patient has been infected. It has been the custom to assume that patients who are negative to the dye test at a titre of $1: 4$ do not suffer from chronic toxoplasmosis.

Recent evidence now suggests that infection with Toxoplasma does not always provoke a dyetest response. Engelbrecht and Franceschetti (1963) 